\title{
PERBANDINGAN TINGKAT KECERDASAN SPIRITUAL ANTARA SISWA MTS NEGERI 4 SLEMAN DAN SMP NEGERI 5 SLEMAN
}

\author{
Siti Wasilatul Fadhilah \\ Program Pasca Sarjana \\ Program Studi Magister Studi Islam \\ Universitas Muhammadiyah Yogyakarta \\ E-mail: sitiwasilatulfadhilah@yahoo.co.id
}

\begin{abstract}
Abstrak
Penelitian ini bertujuan untuk mengetahui perbandingan tingkat kecerdasan spiritual siswa MTs Negeri 4 Sleman dan siswa SMP Negeri 5 Sleman merupakan penelitian kuantitatif dengan menggunakan statistik deskriptif. Untuk menguji kevalidan dan reliabilitas instrumen menggunakan rumus korelasi product moment dari Pearson sedang tehnik analisisnya menggunakan tehnik analisis uji beda. Penelitian ini mengambil sampel sebanyak 100 subyek terdiri dari 60 siswa dari MTs Negeri 4 Sleman dan 40 siswa dari SMP Negeri 5 Sleman. Instrumen penelitian berupa seperangkat angket skala likert mengenai tingkat kecerdasan spiritual siswa. Berdasarkan hasil penelitian yang penulis lakukan dalam penelitian ini, dapat penulis simpulkan bahwa ada perbedaan tingkat kecerdasan spiritual antara siswa MTs Negeri 4 Sleman dan SMPN 5 Sleman dengan hasil uji-t sebesar 3,035 yang lebih besar dari 1,980. Dengan demikian MTs Negeri 4 Sleman sebagai sekolah yang berbasis Islam lebih tinggi tingkat kecerdasan spiritualnya dibanding dengan tingkat kecerdasan spiritual siswa SMP Negeri 5 Sleman.
\end{abstract}

Kata kunci: kecerdasan spiritual, perbedaan, siswa

\begin{abstract}
This research is aimed to know the comparison of spiritual intellegence level among students at MTsN 4 Sleman and SMP Negeri 5 Sleman. This research is intended to know the difference of spiritual intelligence among students of MTsN 4 Sleman. This research is categorised as a quantitative reasearch which implements descriptive qualitative. A product moment correlation, Pearson, is used to asses the validity and reability of the instruments while independent $t$-test is used as the technique of analysis.The sample of this research was 100 subjects that comprise of 60 students at MTsN 4 Sleman and 40 students at SMP Negeri 5 Sleman. As the instrument of the reasearch, quesionnaire test was used (likert scale) which determines spiritual intelligence of students. Finally, the result showed that there is a different upon the using of spiritual intelligence among students at MTsN 4 Sleman and SMP Negeri 5 Sleman with in their life with 3,035 in ttest which is higher than 1,980. Thus, MTsN 4 Sleman as an Islamic school which implemets islamic values has higher level of spiritual intellegence than SMP Negeri 5 Sleman.
\end{abstract}

Keywords: spiritual intellegence, comparison, students

\section{Info Artikel}

Diterima September 2018, disetujui Oktober 2018, diterbitkan Desember 2018

Dipublikasikan Oleh: Program Studi Bimbingan dan Konseling 


\section{PENDAHULUAN}

Manusia adalah makhluk sempurna yang dikaruniai oleh Allah seuatu kecerdasan. Dengan kecerdasan yang dimiliki, manusia dapat berfikir dan memecahkan persoalan yang dihadapinya. Dalam dunia sains telah lama dikenal istilah Kecerdasan Intelektual (Intelligence Quotient). IQ diperkenalkan oleh William Stern dan mejadi sebuah patokan bagi sukses atau tidaknya seseorang, padahal menurut seorang psikolog yang bernama Daniel Goleman IQ hanya menyumbangkan $5-10 \%$ bagi kesuksesan hidup Banyak masyarakat mengira jika seseorang memiliki IQ yang tinggi berarti dia memiliki peluang sukses yang lebih besar dari pada orang yang memiliki IQ yang lebih rendah. Padahal dalam kehidupan nyata orang yang secara akademis memiliki nilai yang tinggi dan berprestasi belum tentu mendapatkan pekerjaan yang layak yang sesuai kapabilitas mereka. Hal tersebut membuktikan bahwa orang yang ber-IQ tinggi tidak menjamin akan mendapatkan kesuksesan dalam hidupnya.

Masyarakat pada umumnya masih menekankan pentingnya nilai dan makna rasional murni yang menjadi tolak ukur IQ dalam kehidupan sehari hari, akan tetapi kecerdasan tidak akan berarti apa-apa bila emosi yang berkuasa . Kecerdasan Emosional merupakan suatu bentuk kecerdasan dalam pengolahan emosi, menurut Daniel Goleman pencetus kecerdasan emosional, keberhasilan seseorang ditentukan oleh 20\% IQ dan $80 \%$ EQ . Oleh sebab itu EQ dipandang lebih penting eksistensinya dibanding dengan IQ.

Selain dua kecerdasan di atas ditemukan lagi sebuah konsep kecerdasan yang tidak hanya berkutat pada ranah otak dan emosi saja, tapi lebih jauh lagi kecerdasan ini merupakan kecerdasan yang mempunyai esensi yang lebih dalam tentang makna hidup seseorang. Kecerdasan tersebut yakni kecerdasan spiritual (SQ). Kecerdasan spiritual yang diyakini sebagai kecerdasan yang mampu memfungsikan kecerdasan intelektual dan kecerdasan emosi secara efektif. Selain itu kecerdasan spiritual memiliki hubungan dengan perilaku prososial. Arah hubungan yang positif menunjukkan bahwa semakin tinggi kecerdasan spiritual maka semakin tinggi perilaku prososialnya. Sebaliknya, jika semakin rendah kecerdasan spiritual maka semakin rendah perilaku prososialnya.

Kecerdasan spiritual merupakan salah satu dari serangkaian kecerdasan yang ada pada diri manusia, yaitu IQ, EQ, SQ. Kecerdasan spiritual adalah suatu kemampuan untuk memberikan makna spiritual terhadap pemikiran, perilaku dan kegiatan serta mampu mengkombinasikan 3 kecerdasan yang lain secara komprehensif. Kecerdasan spiritual merupakan kecerdasan yang menyinergikan 2 kecerdasan lain secara komprehensif. Selain itu 
kecerdasan spiritual dapat disebut sebagai kecerdasan yang berasal dari dalam hati, menjadikan manusia kreatif ketika mereka dihadapkan pada masalah pribadi, dan mencoba melihat makna yang terkandung didalamnya, serta menyelesaikannya dengan baik agar memperoleh ketenangan dan kedamaian hati.

Spiritualitas atau agama sebagai kebutuhan paling mendasar bagi setiap manusia, mempunyai fungsi dan pengaruh yang kuat bagi diri individu untuk mengatasi dan menyikapi berbagai permasalan yang sukar, menekan dan mengganggu ketahanan mental individu. Spiritualitas memiliki dampak positif, tidak hanya membebaskan manusia dari rasa kegelisahan dan kecemasan, bahkan hubungan rohaniah antara manusia dan Tuhannya, memberi harapan, menguatkan kemauan, dan membekali kekuatan yang luar biasa sehingga memungkinkan manusia untuk dapat menghadapi segala permasalahan dan melaksanakan tugas dengan baik.

Konsep Kecerdasan spiritual atau Spiritual Quotient (SQ) pertama kali dicetuskan oleh Danah Zohar dan Ian Marshall, mereka mendefinisikan kecerdasan spiritual sebagai bentuk dari kecerdasan untuk menghadapi persoalan makna atau value. Zohar berpendapat bahwa pengenalan diri terutama kesadaran diri adalah suatu kesadaran internal otak, Zohar juga berpendapat bahwa proses yang berlangsung pada otak sendirilah tanpa pengaruh panca indra dan dunia luar yang membentuk kesadaran sejati manusia.

Dengan SQ manusia mampu memandang kehidupan dengan penuh makna, tidak sebatas ukuran materiil saja yang dicari akan tetapi kehidupan imateriil yakni kepercayaan kepada Tuhannya. Orang yang cerdas secara spiritual membentuk suatu kesadaran bahwa eksistensinya tidak terjadi begitu saja dan bukan merupakan suatu kebetulan akan tetapi dia sadar sepenuhnya bahwa eksistensinya di dunia merupakan maha karya dari sang pencipta.

SQ tidak terbatas hanya pada pemberian makna dalam setiap kegiatan atau perbuatan yang dilakukan oleh seseorang akan tetapi SQ adalah kemampuan memberikan makna spiritual dalam setiap apa yang dia perbuat dan yang dia kerjakan, ada suatu hubungan yang integral antara apa yang terjadi dalam kehidupan manusia dengan campur tangan yang Maha Kuasa.

Disamping itu berdasarkan jurnal penelitian yang dilakukan oleh Deisa Iriani Rampisela, Sefti Rompas dan Reginus Malara menyatakan bahwa kecerdasan emosional dan kecerdasan spiritual berpengaruh terhadap prestasi belajar siswa di SMP Katolik ST.Fransiskus Pineleng Juga jurnal penelitian yang dilakukan oleh Theresia Oktaviani Nay dan Dewanti Ruparin Diah menyatkan bahwa ada hubungan antara kecerdasan spiritual dengan resiliensi pada siswa yang mengikuti program akselerasi Sekolah 
Menengah Atas Negeri di kota Malang. Dimana jika siswa memiliki kecerdasan spiritual yang baik maka akan juga memiliki resiliensi yang baik pula.

Pada masa modern ini banyak terjadi degradasi moral pada masyarakat, banyak terjadi kasus pembunuhan, bunuh diri, perampokan karena kemiskinan dan lain sebagainya. Hal tersebut terjadi tentunya disebabkan tidak adanya nilai spiritual yang tertanam dalam diri manusia, bukan hanya terbatas bahwa nilai spiritual itu berkaitan dengan pengetahuan seseorang terhadap suatu permasalahan agama akan tetapi jauh lebih penting nilai spiritual itu adalah tentang bagaimana seseorang memahami dan melaksanakan agama. Kecerdasan spiritual memiliki hubungan dengan prilaku social siswa sebagaimana penelitian yang yang dilakukan oleh Titin Hartini (2017) yang menyatakan bahwa Terdapat pengaruh kecerdasan spiritual (SQ) dengan perilaku sosial siswa secara signifikan dan pola hubungan searah sebesar 45,6\% termasuk kategori kuat, searah dan positif.

SQ tidak dapat datang dengan begitu saja pada diri manusia akan tetapi perlu suatu proses untuk bisa cerdas secara spiritual yakni dengan pendidikan. Peranan pendidikan khususnya pendidikan Islam di kalangan umat Islam merupakan salah satu bentuk manifestasi cita-cita hidup untuk melestarikan, menanamkan dan mentransformasikan nilai-nilai Islam kepada generasi penerusnya sehingga nilai-nilai kultural religius yang dicitacitakan dapat tetap berfungsi dan berkembang sesuai dengan kemajuan zaman dan tehnologi.

Kecerdasan spiritual diakui memiliki hubungan dengan prestasi siswa sebagaimana penelitian yang dilakukan oleh Patel dan Ghani (2016) yang menyatakan adanya hubungan yang signifikan antara prestasi dan kecerdasan spiritual. Hal ini dikuatkan pula oleh Saranya dan Sangetha (2015) yang meneliti hubunganya dengan prestasi belajar IPA siswa SMP. Selanjutnya, Bozorgi dan Bazorgi (2016) menemukan bahwa kecerdasan spiritual berpengaruh secara positif terhadap kesehatan mental seseorang. Riset lain yang dilakukan oleh Hema dan Advani (2015) menyatakan bahwa kecerdasan spiritual berpengaruh secara positif terhadap kesehatan secara umum dan kesejahteraan seseorang.

Seperti yang sering kita saksikan di media massa, banyak sekali peristiwa yang mewarnai realita dunia pendidikan mulai dari kondisi moral remaja dan generasi muda khususnya nampak makin memprihatinkan yang belum mampu menumbuhkan kader bangsa yang mempunyai karakter, religius, mandiri dan anti korupsi. Tawuran pelajar banyak terlihat di sana sini, perilaku kriminal dan berbagai perbuatan yang a moral dewasa ini banyak dilakukan para pelajar, dan hal itu dianggap sebagai 
hal yang lumrah dan dianggap sebagai bagian dari pelaksanaan budaya negatif. Akankah itu bukti praktek pendidikan yang ada belum mampu menyentuh secara keseluruhan domain akal dan terutama menyentuh jiwa dan hati mereka, sehingga terlihat orientasi pengembangan intelektual menjadi prioritas utama dari suatu pendidikan dan tanpa diimbangi dengan kekuatan spiritual.

Selama ini masyarakat pada umumnya masih beranggapan bahwa lembaga pendidikan MTs merupakan lembaga pendidikan pilihan kedua setelah SMP Negeri, hal ini terbukti dari hasil perolehan siswa ketika PPDB (Penerimaan Peserta Didik baru) berlangsung lembaga pendidikan MTs jumlah input nilai pendaftarnya lebih rendah dari pada SMP Negeri. MTs Negeri 4 Sleman pada tahun pelajaran 2017/2018 NEM tertinggi adalah 258,5 dan terendah 193,50 . Sedangkan SMP Negeri 5 Sleman NEM tertinggi adalah 274,50 dan terendah 222,50 . Namun pada kenyataannya dari hasil wawancara kami dengan guru agama SMP Negeri 5 Sleman bahwa siswa yang berasal dari lingkungan/keluarga yang agamis cenderung untuk memasukkan putra/putrinya ke MTs Negeri 4 Sleman dari pada ke SMP Negeri 5 Sleman . Perlu diketahui bahwa lokasi MTs Negeri 4 Sleman dengan SMP Negeri 5 Sleman berada dalam satu wilayah kecamatan yang hanya berjarak kurang lebih $3 \mathrm{Km}$.
Sebagai lembaga pendidikan yang bernuansa keislaman, kondisi MTs terasa lebih menyejukkan. Berbagai aktivitas ibadah banyak dilakukan secara rutin dan intensif oleh siswa. Mulai dari ibadah sholat fardhu berjamaah, sholat dhuha, hingga kebiasaan menghafal alQur'an. Selain itu porsi pendidikan agama di MTs jauh lebih besar daripada di SMP. Porsi pendidikan agama di SMP hanya 3 jam pelajaran perminggu. Sementara di MTs porsi pendidikan agama 11 jam pelajaran perminggu. Hal ini tentu saja akan mempengaruhi kondisi tingkat kecerdasan spriritual siswa.

Untuk itu diperlukan bekal pendidikan agama, agar kelak dewasa tidak menjadi manusia yang melakukan korupsi, kolusi dan nepotisme, melakukan kejahatan intelektual, merusak alam untuk kepentingan pribadi. Faktor pendorong adanya tantangan diatas dikarenakan longgarnya pegangan terhadap dimensi spiritualitas individu, karena hanya mengedepankan ilmu pengetahuan dalam dimensi intelektual, sehingga nampaknya pendidikan saat ini belum berhasil membentuk generasi muda Indonesia yang selain cerdas intelektual juga cerdas spiritual. Pendidikan keagamaan harus kembali kita jadikan pelajaran penting untuk mencegah dari tindakan yang tidak sesuai dengan moral,nilai yang berlaku, sehingga sikap anak didik menjadi sesuai dengan tujuan pendidikan keagamaan yang pada esensi utamanya 
ialah mengharapkan terbentuknya anak didik yang iman dan taqwa.

Salah satu aspek kecerdasan spiritual adalah kemampuan untuk menggunakan sumber-sumber spiritual dalam mengatasi permasalahan hidupnya. Sumber spiritual yang paling menonjol adalah sumber-sumber yang berkaitan dengan agama, dalam hal ini adalah agama Islam. Oleh karena itu pentingnya masalah ini diteliti adalah untuk membuktikan apakah siswa MTs Negeri 4 Sleman sebagai sekolah yang bernuansa keislaman, seharusnya memiliki tingkat kecedasan spiritual yang lebih dibanding dengan SMP Negeri 5 Sleman. Hal ini karena siswa MTs sudah terbiasa dalam kondisi Islami serta memperoleh porsi yang lebih dalam Pendidikan Agama Islam.

\section{METODE PENELITIAN}

Penelitian yang berjudul Perbandingan Tingkat Kecerdasan Spiritual Antara Siswa MTs Negeri 4 Sleman dan SMP Negeri 5 Sleman merupakan penelitian kuantitatif dengan menggunakan statistik deskriptif. Untuk menguji kevalidan dan reliabilitas instrumen menggunakan rumus korelasi product moment dari pearson sedang tehnik analisisnya menggunakan tehnik analisis uji beda.

\section{HASIL DAN PEMBAHASAN}

Tingkat kecerdasan spiritual siswa MTs Negeri 4 Sleman.

Data Hasil angket terhadap tingkat kecerdasan spiritual siswa MTsN 4 Sleman

Peserta didik yang diteliti dalam penelitian ini adalah siswa MTs Negeri 4 Sleman. Data ini berfokus kepada tingkat kecerdasan spiritual siswa. Pengumpulan data mengenai tingkat kecerdasan spiritual telah dilakukan menghasilkan data berupa skor. Instrumen pengumpulan data berupa skala likert yang digunakan peneliti untuk memperolah data tingkat kecerdasan spiritual berhasil menjaring data berupa skor. Selanjutnya skor tersebut dianalisis menggunakan SPSS 22. Hasilnya seperti tertera dalam tabel berikut :

Tabel 1.

Variabilitas Tingkat Kecerdasan Spiritual Siswa MTsN 4 Sleman

\begin{tabular}{|c|c|}
\hline & $\begin{array}{c}\text { Skor Tingkat Kecerdasan Spiritual Siswa } \\
\text { MTsN 4 Sleman }\end{array}$ \\
\hline $\mathrm{N}$ & 60 \\
\hline Mean & 61,58 \\
\hline Median & 61,00 \\
\hline Mode & 59,00 \\
\hline Minimum & 47 \\
\hline Maximum & 79 \\
\hline Sum & 3695 \\
\hline
\end{tabular}


Untuk memperoleh gambaran yang menyajikan data secara visual dalam lebih jelas, berikut ini penulis bentuk grafik.

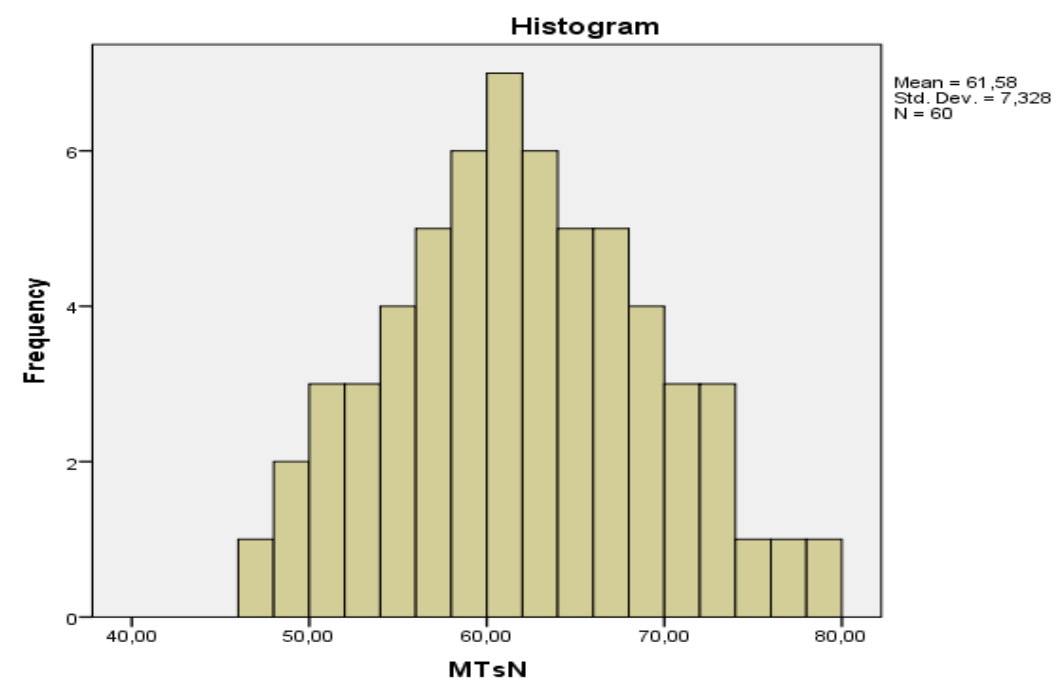

Gambar 1

Grafik skor tingkat kecerdasan spiritual siswa MTs N 4 Sleman

Dari hasil tingkat kecerdasan spiritual siswa MTsN 4 Sleman diatas menunjukkan nilai mean skor tingkat kecerdasan spiritual siswa MTsN 4
Sleman sebesar 61,58. Nilai rerata ini selanjutnya dibandingkan dengan tabel berikut :

Tabel 2.

Tolok Ukur tingkat kecerdasan spiritual siswa MTsN 4 Sleman

\begin{tabular}{|c|c|}
\hline Interval Skor & Tingkat Kecerdasan Spiritual \\
\hline $84-100$ & Sangat Tinggi \\
\hline $68-83$ & Tinggi \\
\hline $52-67$ & Sedang \\
\hline $36-51$ & Rendah \\
\hline $20-35$ & Sangat Rendah \\
\hline
\end{tabular}

Berdasarkan dalam tabel maka tingkat kecerdasan spiritual siswa MTsN 4 Sleman masih dalam kategori sedang. Hal ini masih cukup memprihatinkan, apalagi mengingat madrasah merupakan pendidikan berbasis islam. Untuk itu kecerdasan spiritual penting untuk ditingkatkan.
Tingkat kecerdasan spiritual siswa SMP Negeri 5 Sleman

Data Hasil angket terhadap tingkat kecerdasan spiritual siswa SMP Negeri 5 Sleman

Peserta didik yang diteliti dalam penelitian ini adalah siswa SMP Negeri 5 Sleman. Data ini fokus mengenahi tingkat kecerdasan 
spiritual siswa. Pengumpulan data mengenai tingkat kecerdasan spiritual telah dilakukan menghasilkan data berupa skor. Instrumen pengumpulan data berupa skala likert yang digunakan peneliti untuk memperolah

\section{Tabel 3}

Variabilitas Tingkat Kecerdasan Spiritual Siswa SMP Negeri 5

\begin{tabular}{|c|c|}
\hline & $\begin{array}{c}\text { Skor Tingkat Kecerdasan Spiritual Siswa } \\
\text { SMP N 5 Sleman }\end{array}$ \\
\hline $\mathrm{N}$ & 40 \\
\hline Mean & 57,50 \\
\hline Median & 57 \\
\hline Mode & 57 \\
\hline Minimum & 48 \\
\hline Maximum & 70 \\
\hline Sum & 2300 \\
\hline
\end{tabular}

Untuk memperoleh gambaran yang menyajikan data secara visual dalam lebih jelas, berikut ini penulis bentuk grafik.

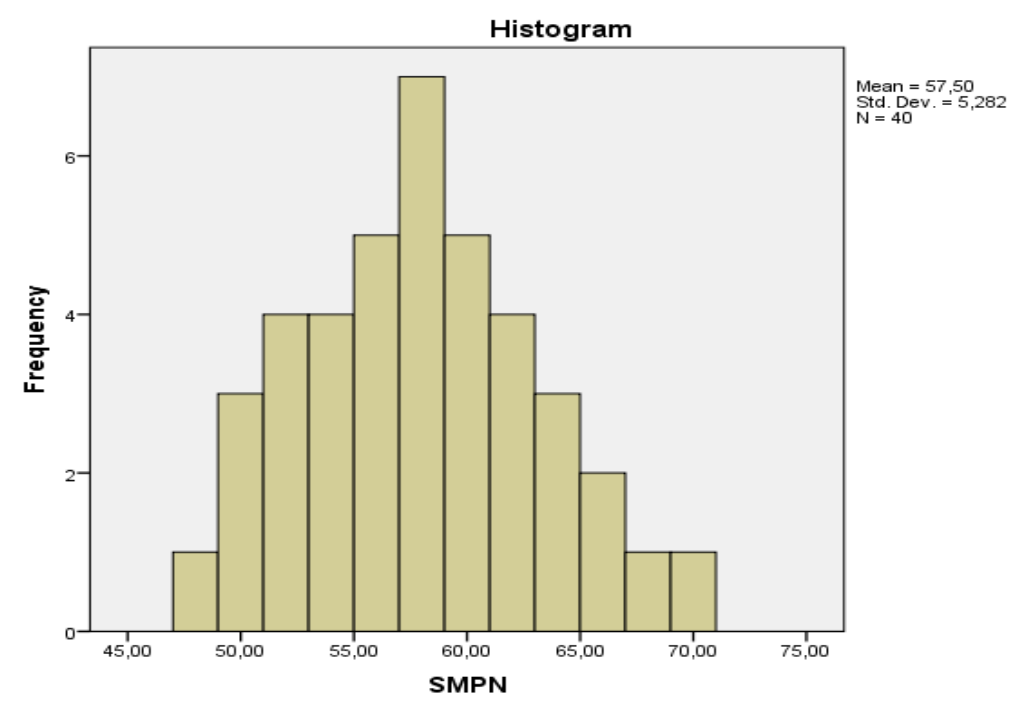

Gambar 2

Grafik skor tingkat kecerdasan spiritual siswa SMP Negeri 5 Sleman

Dari hasil tingkat kecerdasan spiritual siswa SMP Negeri 5 Sleman diatas menunjukkan nilai mean skor SMP Negeri 5 Sleman sebesar 57,50. Nilai rerata ini selanjutnya dibandingkan dengan tabel berikut : tingkat kecerdasan spiritual siswa 
Tabel 4.

Tolok Ukur tingkat kecerdasan spiritual siswa MTsN 4 Sleman

\begin{tabular}{|c|c|}
\hline Interval Skor & Tingkat Kecerdasan Spiritual \\
\hline $84-100$ & Sangat Tinggi \\
\hline $68-83$ & Tinggi \\
\hline $52-67$ & Sedang \\
\hline $36-51$ & Rendah \\
\hline $20-35$ & Sangat Rendah \\
\hline
\end{tabular}

Berdasarkan dalam tabel diatas maka tingkat kecerdasan spiritual siswa SMP Negeri 5 Sleman masih dalam kategori sedang. Hal ini masih cukup memprihatinkan. Untuk itu kecerdasan spiritual penting untuk ditingkatkan.

Perbedaan tingkat kecerdasan spiritual siswa MTs Negeri 4 Sleman dan siswa SMP Negeri 5 Sleman

Uji Perbedaan tingkat kecerdasan spiritual siswa MTs Negeri 4 Sleman dan siswa SMP Negeri 5 Sleman.

\section{Uji Prasyarat Analisis}

Sebelum proses analisis data, terlebih dahulu harus dilakukan uji prasyarat analisis data. Uji ini dilakukan untuk mengetahui normalitas sebaran dan homogenitas sampel. Setelah uji prasyarat ini dilakukan tuntas, barulah analisis terhadap data penelitian dilakukan. Berikut ini diuraikan hasil uji normalitas sebaran dan uji homoginitas sampel menggunakan bantuan statistik SPSS 22 .

\section{Uji Normalitas Sebaran}

Uji normalitas sebaran bertujuan untuk mengetahui apakah skor suatu variabel berdistribusi normal atau tidak. Dalam penelitian ini variabel yang diuji normalitas sebarannya adalah skor tingkat kecerdasan spiritual siswa MTsN 4 Sleman dan skor tingkat kecerdasan spiritual siswa SMPN 5 Sleman. Teknik statistik yang digunakan dalam menguji normalitas dalam penelitian ini adalah teknik Kolmogorov-Smirnov.

Setelah dilakukan penghitungan menggunakan SPSS.22, maka hasil penghitungannya adalah sebagai berikut: 
Tabel 5.

Rangkuman Hasil Uji Normalitas Sebaran Skor

\begin{tabular}{|ll|r|r|}
\hline \multicolumn{4}{|c|}{ One-Sample Kolmogorov-Smirnov Test } \\
\hline $\mathrm{N}$ & \multicolumn{1}{|c|}{ MTsN } & \multicolumn{1}{c|}{ SMP } \\
Normal Parameters ${ }^{\mathrm{a}, \mathrm{b}}$ & Mean & 60 & 40 \\
& Std. Deviation & 61,5833 & 57,5000 \\
Most Extreme Differences & Absolute &, 32836 & 5,28180 \\
& Positive &, 048 &, 063 \\
& Negative &, 048 &, 063 \\
Test Statistic & &,- 046 &,- 046 \\
Asymp. Sig. (2-tailed) & &, 048 &, 063 \\
\hline
\end{tabular}
a. Test distribution is Normal.
b. Calculated from data.
c. Lilliefors Significance Correction.
d. This is a lower bound of the true significance.

Berdasarkan hasil uji normalitas SMP Negeri 5 Sleman hasilnya sebaran dengan teknik Kolmogorov- normal. Grafik berikut ini Smirnov dapat disimpulkan bahwa menunjukkan secara visual sebaran sebaran tingkat kecerdasan spiritual variabel.

siswa MTs Negeri 4 Sleman dengan

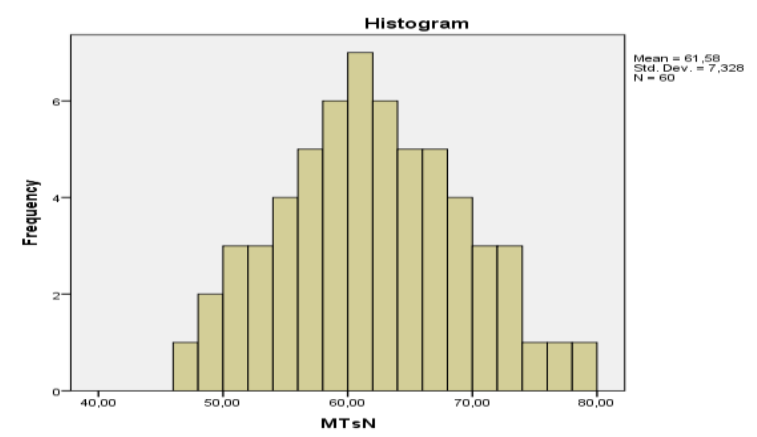

Gambar 3.

Grafik Normalitas Tingkat Kecerdasan Spiritual Siswa Mts Negeri 4 Sleman

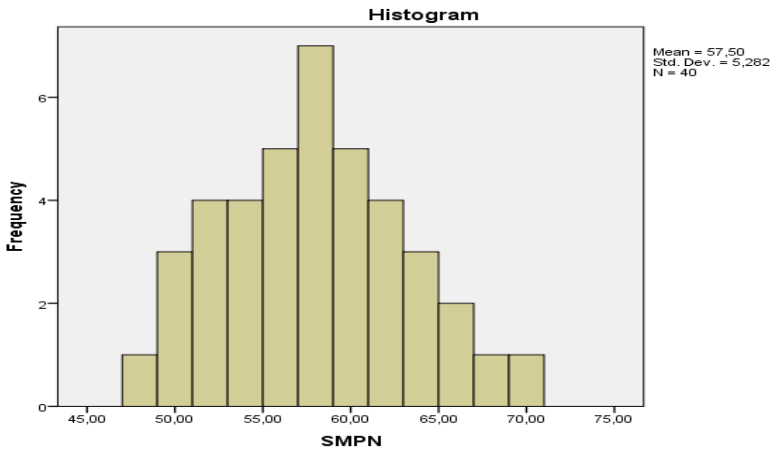

Gambar 4

Grafik Normalitas Tingkat Kecerdasan Spiritual Siswa SMP Negeri 5 Sleman 


\section{Uji Hipotesis Penelitian}

Dalam penelitian perbandingan tingkat kecerdasan spiritual siswa MTsN 4 Sleman dan siswa SMP N 5 Sleman ini dilakukan analisis komparasi ( uji beda) dengan teknik uji-t menggunakan program SPSS. 22.
Uji statistik ini untuk mengetahui ada tidaknya perbedaan yang signifikan antara tingkat kecerdasan spiritual siswa MTsN 4 Sleman dan siswa SMP N 5 Sleman. Hasil uji-t terlihat dalam tabel di bawah ini.

Tabel 6

Hasil Uji-T Menggunakan SPSS.22 Independent Samples Test

\begin{tabular}{|c|c|c|c|c|c|c|c|c|c|}
\hline & $\begin{array}{r}\text { Leve } \\
\text { Tes } \\
\text { Equa } \\
\text { Varia } \\
\end{array}$ & $\begin{array}{l}\text { ne's } \\
\text { for } \\
\text { ity of } \\
\text { nces } \\
\end{array}$ & \multicolumn{7}{|c|}{ t-test for Equality of Means } \\
\hline & \multirow[b]{2}{*}{$\mathrm{F}$} & \multirow[b]{2}{*}{ Sig. } & \multirow[b]{2}{*}{$\mathrm{t}$} & \multirow[b]{2}{*}{ df } & \multirow{2}{*}{$\begin{array}{l}\text { Sig. } \\
(2- \\
\text { tailed) }\end{array}$} & \multirow{2}{*}{$\begin{array}{l}\text { Mean } \\
\text { Differ } \\
\text { ence }\end{array}$} & \multirow{2}{*}{$\begin{array}{c}\text { Std. } \\
\text { Error } \\
\text { Differe } \\
\text { nce }\end{array}$} & \multicolumn{2}{|c|}{$\begin{array}{c}95 \% \\
\text { Confidence } \\
\text { Interval of the } \\
\text { Difference }\end{array}$} \\
\hline & & & & & & & & Lower & Upper \\
\hline $\begin{array}{ll}\text { KS } & \text { Equal } \\
\text { variances } \\
\text { assumed } \\
\text { Equal } \\
\text { variances } \\
\text { not } \\
\text { assumed }\end{array}$ & $\begin{array}{r}4,31 \\
0\end{array}$ & ,040 & 3,236 & 97,350 & ,002 & 4,083 & 1,262 & 1,579 & 6,588 \\
\hline
\end{tabular}

Pada tabel di atas terlihat nilai $\mathrm{t}$ sebesar 3,035 untuk variabel tingkat kecerdasan spiritual. Nilai ini jelas signifikan karena lebih besar dengan nilai t tabel yang hanya sebesar 1,980 untuk interval kepercayaan yang sama. Jadi, perbedaan tingkat kecerdasan spiritual antara siswa MTs Negeri 4 Sleman dan siswa SMP Negeri 5 Sleman tersebut signifikan.

\section{PEMBAHASAN}

Penelitian Perbandingan tingkat kecerdasan spiritual antara siswa MTs Negeri 4 Sleman dengan siswa SMP Negeri 5 Sleman dengan subjek 60 siswa MTs Negeri 4 Sleman dan 40 siswa SMP Negeri 5 Sleman ini telah berhasil menjaring data yang telah dideskripsikan. Data tersebut selanjutnya diolah dan dianalisis. Setelah menempuh langkah analisis, maka untuk mendapatkan pemahaman secara tuntas terhadap hasil penelitian maka selanjutnya penulis akan melakukan pembahasan terhadap hasil penelitian tersebut.

Dengan hasil uji-t membuktikan bahwa tingkat kecerdasan spiritual siswa MTsN 4 Sleman lebih tinggi dibandingkan dengan tingkat kecerdasan spiritual siswa SMPN 5 Sleman. Hal ini ditunjukkan oleh hasil uji-t yang menunjukkan taraf signifikansi yang tinggi yaitu $\mathrm{t}=$ 3,035. lebih besar dari 1,980. Dengan 
demikian penulis yakin bahwa tingkat kecerdasan spiritual siswa MTsN 4 Sleman lebih tinggi dibandingkan dengan tingkat kecerdasan spiritual siswa SMP 5 Sleman.

Dengan demikian Ho yang berbunyi tidak ada perbedaan tingkat kecerdasan spiritual antara siswa MTsN 4 Sleman dengan siswa SMPN 5 Sleman yang signifikan ditolak. Sedangkan Ha yang berbunyi terdapat perbedaan tingkat kecerdasan spiritual antara siswa MTsN 4 Sleman dengan siswa SMPN 5 Sleman yang signifikan diterima.

Oleh karena itu perlu diupayakan untuk meningkatkan kecerdasan spiritual siswa karena kecerdasan spiritual dapat disebut sebagai kecerdasan yang berasal dari dalam hati, menjadikan manusia kreatif ketika mereka dihadapkan pada masalah pribadi, dan mencoba melihat makna yang terkandung didalamnya, serta menyelesaikannya dengan baik agar memperoleh ketenangan dan kedamaian hati. Kecerdasan spiritual terbukti mempengaruhi kesuksesan belajar. Disamping itu menurut penelitian Kasih Haryo Basuki (2015) bahwa kecerdasan spiritual berperan sebagai faktor pemicu lahirnya kesadaran untuk mencapai prestasi belajar yang optimal.

Adapun upaya-upaya yang dilakukan untuk meningkatkan kecerdasan spiritual adalah sebagaimana penelitian yang dilakukan oleh Lufiana Harnany Utami (2015) yaitu Pertama tafakur kepada Allah yang bertujuan mendorong siswa merenungi semua ciptaan Allah serta apa yang telah diberikan Allah kepadanya. Upaya kedua yang dikerahkan adalah melakukan ibadah-ibadah sunah seperti shalat dhuha berjama'ah dan mengaji bersama. Berikutnya adalah upaya ketiga yang dilakukan SDI Tompokersan Lumajang dengan cara membiasakan dzikir pada semua warga sekolah. Hal ini selaras dengan penelitian yang dilakukan oleh Gammar Al Haddar (2016) bahwa Berbagai kegiatan yang ada dalam kegiatan ekstrakurikuler ROHIS SMP YAPAN Indonesia, dimulai dari program harian, program mingguan dan program tahunannya mendukung terhadap pengembangan kecerdasan spiritual siswanya. Seperti, kegiatan muhadharah, shalat jum'at bersama, shalat dhuhur berjamaah dan pengajian Al-Qur'an. Serta peringatan hari besar dalam Islam.

\section{KESIMPULAN}

Setelah menempuh prosedur penelitian yang telah direncanakan akhirnya penenlitian ini menghasilkan kesimpulan sebagai berikut :

1. Rata-rata tingkat kecerdasan spiritual siswa MTs Negeri 4 Sleman adalah 61,583 Angka ini berada dalam level sedang. Angka ini sedikit lebih tinggi dibanding perolehan skor siswa SMP.

2. Rata-rata tingkat kecerdasan spiritual siswa SMPN 5 Sleman adalah 57,50. Angka ini berada 
dalam level sedang, tetapi sedikit lebih rendah daripada skor MTs.

3. Ada perbedaan tingkat kecerdasan spiritual antara siswa MTs Negeri 4 Sleman dan SMPN 5 Sleman dengan hasil uji $\mathrm{t}$ sebesar 3,035 yang lebih besar dari 1,980.

\section{SARAN}

Agar penelitian ini lebih bermakna, maka berikut ini penulis menyampaikan beberapa saran kepada beberapa pihak:

1. Kepada Kepala Madrasah dan kepala Sekolah agar lebih memperhatikan penanaman kecerdasan spiritual guna meningkatkan tingkat kecerdasan spiritual para siswa.

2. Kepada para guru dianjurkan agar selalu berusaha menjaga dan menghadirkan suasana spiritualitas siswa dalam pembelajaran dengan cara selalu memulai dan mengakhiri pelajaran dengan berdoa, mengintegrasikan materi pembelajaran dengan nilai keimanan sehingga siswa merasakan adanya kesatuan makna dalam pembelajaran

3. Kepada orang tua sebaiknya menyediakan berbagai sarana yang dibutuhkan unutk meningkatkan spiritualitas anak seperti menyediakan ruang ibadah dirumah, mengajak diskusi tentang berbagai permasalahan agama dan kejiwaan
4. Kepada siswa sebaiknya aktif mengikuti berbagai kajian keagamaan, rajin membaca bukubuku agama, rajin beribadah dan mendekatkan diri kepada Allah SWT, mengadakan perenungan tentang makna sebuah kehidupan.

\section{DAFTAR PUSTAKA}

Agustian, Ary Ginanjar. 2005. Rahasia Sukses Membangun Kecerdasan Emosional dan Spiritual EQ (Emotional, Spiritual dan Questient). Jakarta: Penerbit Agra.

Al Haddar, Gamar. 2016. Upaya Pengembangan Kecerdasan Spiritual Siswa Melalui Kegiatan Ekstrakurikuler Rohani Islam Di Smp Yapan Indonesia. Depok. Jurnal Pendas Mahakam.

As'ad, M Djalali. 2012. Kecerderdasan Emosi. Kecerdasan Spiritual dan Perilaku Prososial Santri Pondok Pesantren Nasyrul Ulum Pamekasan Persona. Jurnal Psikologi Indonesia. Universitas 17 Agustus 1945. Surabaya.

Az-Zumaro, Kirom Lutfil. 2011. Aktifitas Energi Doa \& Dzikir Khusus Untuk Kecerdasan Super (Otak + Hati). Jogjakarta: Diva Press.

Basuki, Kasih Haryo. 2015. Pengaruh Kecerdasan Spiritual Dan Motivasi Belajar Terhadap Prestasi Belajar Matematika. Jurnal Formatif. 
Bozorgi, Mahdi Dasht. Zahra Dasht Bozorgi. 2016. The Relationship between Spiritual Intelligence, Coping Strategies, and Mental Health among Students. International Journal Of Humanities And Cultural Studies Issn 2356-5926. Islamic Azad University. Ahvaz branch. Ahvaz. Iran.

Deisa, Iriani Rampisela dkk. 2017. Hubungan Kecerdasan Emosional Dan Kecerdasan Spiritual dengan Prestasi Belajar Siswa Di Smp Katolikst. Fransiskus Pineleng. e-journal Keperawatan (e-Kp). Universitas Sam Ratulangi. Manado Sulawesi Utara.

Ghufron, M. Nur. 2016. Spiritualitasdan Kesuksesan Belajar: Studi Meta Analisis. Jurnal Penelitian Pendidikan Islam.

Goleman, Daniel. 1997. Emotional Intelligence. Jakarta: Gramedia Pustaka Utama.

G, Ms Hema. dan Dr. Vinita Advani. 2015. Spiritual Intelligence: At a Glance!. The International Journal of Indian Psychology.

Hartini, Tintin. 2017. Pengaruh Kecerdasan Intelektual (Iq). Kecerdasan Emosional (Eq) Dan Kecerdasan Spiritual (Sq) Terhadap Perilaku Sosial Siswa Smpn 1 Kadugede Kabupaten Kuningan, Jurnal Ilmiah Kajian Islam.
Inayatussalamah, Iin. 2015. Kecerdasan Spiritual Dalam Majelis Pesona Ilahi Ponorogo. Jurnal Cendekia Vol. 13 No. 2, STAIN Ponorogo.

Nasution, Ahmad Taufik. 2009. Melejitkan SQ dengan Prinsip 99 Asmaul Khusna. Jakarta: Gramedia Pustaka Utama

Nay, Oktaviani Theresia. Dewanti Ruparin Diah. 2013. Hubungan Kecerdasan Spiritual Dengan Resiliensi Pada Siswa Yang Mengikuti Program Akselerasi. Jurnal Psikologi Tabularasa. Fakultas Psikologi Universitas Merdeka Malang.

Patel, Sabbal. Prof Asararul Ghani. 2016. A Relationship between Spiritual Intelligence and Emotional Intelligence of Higher Secondary students in relation to Academic Achievement. BRDU International Journal of Multidisciplinary Research. Barkatullah University. M.P (Madhya Pradesh) India.

Saranya, R. Mrs. T. Sangeetha. 2017. A Study Of Spiritual Intelligence In Relation To Achievement In Science Among Secondary School Students In Coimbatore Educational District International Journal of Research -Granthaalayah. RVS College of Education, India.

Utami, Lufiana Harnany. 2015. Pengembangan Kecerdasan Spiritual Siswa Di Sd Islam Tompokersan Lumajang. 
Psympathic. Jurnal Ilmiah Yuningsih. 2014. Menguatkan

Psikologi.

Yantiek, Ermi. 2014, Kecerdasan Emosi. Kecerdasan Spiritual Dan Perilaku Prososial Remaja. Persona. Jurnal Psikologi Indonesia. Universitas 17 Agustus 1945. Surabaya.
Kembali Pendidikan Keagamaan

Dan Moral Anak Didik. Jurnal Edisi Agustus 2014 Volume VIII No. 2. UIN Sunan Gunung Djati Bandung. 